\title{
Teaching and Learning of Probability
}

\author{
Per Nilsson and Jun Li
}

\section{Aims and Focus}

Probability has strong roots in the curricula of many countries but is relatively new in others. And although probability has been introduced into the mainstream school mathematics curricula in many countries, research does not necessarily support a rapid inclusion into the curriculum because many problems in teaching and learning probability are still unsolved. For example, should probability be taught to all students? When should students be introduced to probability? What is probability literacy? How is probability literacy developed? What kind of knowledge do teachers need in order to teach probability in more concrete, meaningful and effective ways? How do we facilitate the development of such teaching knowledge? How could investigating students' conceptions of probability from various perspectives further inform our teaching? At ICME 12 in Seoul, Topic Study Group 11 provided a forum for presentations and discussion from an international view about the current state and important new trends in research and practice related to the teaching and learning of probability.

Traditionally, the teaching of probability concerns two different interpretations of probability: (1) a classical conception, where probability is based on combinatorics or formal mathematics, and (2) a frequency conception, where probability is

Organizers Team Chairs: Per Nilsson (Sweden), Jun Li (China); Team Members: Enriqueta Reston,(Philippines), Egan Chernoff (Canada), Kyeong-Hwa Lee (Korea), Efi Paparistodemou (Cyprus); Liaison IPC Member: Gail Burrill (USA).

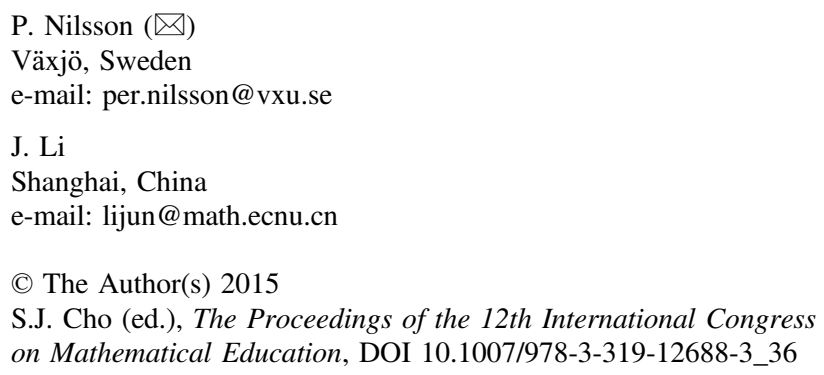


based on empirical evidence and long-termed behaviour of random phenomena. The Topic Study Group (TSG) tried to look beyond these two interpretations and consider as the first focus how to teach probability concepts in ways that develop understanding and support the use of probability to make rational decisions in situations that affect peoples' lives and their work. It is important to note that the notion of probability as used in the Topic Study Group included aspects of chance, randomness, risk and its relationship to statistics.

The second focus was on teachers' knowledge for teaching probability. While teacher knowledge is critical for effective teaching of probability, very few studies deal with teacher knowledge and they (including the papers presented in the TSG) indicate that neither pre-service nor in-service teachers have enough knowledge for teaching probability. There is a growing global interest in learning what kind of knowledge teachers need to be able to effectively teach probability concepts and how to facilitate the development of such teacher knowledge. To promote more discussion and research in this area, the plenary panel discussion was narrowed to teacher knowledge for probability teaching.

The paper contributions were structured according to four general themes: Curriculum Development and Policies, Research on Students' Thinking and Reasoning, Probability Literacy and Instructional Challenges, Teacher Knowledge in Probability Teaching. They were presented in four sessions allotted to TSG 11.

The first three sessions began with an invited keynote speech: Ramesh Kapadia (United Kingdom), Manfred Borovcnik (Austria), Iddo Gal (Israel). The aim of these lectures was to sketch an overall picture of the TSG theme. A plenary panel was arranged for the last session that included all three keynote speakers and liaison, Gail Burrill, who were invited to reflect on the theme. Each session was closed by a summary by the session chair.

\section{Session 1: Curriculum Development and Policies}

Egan Chernoff, chaired the session., which began with opening remarks by co-chairs Per Nilsson and Jun Li, followed by an invited keynote speech by Ramesh Kapadia, and presentations by Jenny Gage (United Kingdom), Xianghui Wu (China).

Kapadia's address reviewed the main changes in the research related to probability education from the Piagetian-Fischbein era, the Kahneman_Tversky era to the current period. He summarized key research in the three eras and stressed the importance of developing new ideas from the past. He also provided an overview of curriculum development in England since the 1970s in the hope that some of the lessons can be applied elsewhere of the world. Based on the research and curriculum development, he suggested introducing probability at the elementary level, using a judicious mixture of subjective theory, a priori theory and frequentist theory of probability.

Gage presented an on-going project investigating mathematical modelling as a means for the learning of probability. She described school trials solving two 
problems by students between 10 and 14 years of age. The results suggested that the modelling approach and using values from the tally (natural frequencies), not probability, seemed to help students grasp the essence of the analysis of a problem and enabled them to use tree diagrams and 2-way contingency tables successfully.

Wu's paper was based on the belief that learning by game-playing should be central in children and adolescents' education as it stimulates the learning processes of flexibility, enjoyment, and adaptability. He shared with us his teaching experiences using three carefully designed games in his Grade 9 class.

In summarizing the session, Chernoff pointed to how the three talks highlighted that terms like misconceptions and subjective probability require serious discussion in future research. He raised the question of whether the frequency interpretation of probability should be emphasized with more care. He called on the need to address the teaching of risk and suggested we may benefit from research relevant to other TSGs, such as mathematical applications and modelling in the teaching and learning of mathematics.

\section{Session 2: Research on Students' Thinking and Reasoning}

Per Nilsson was the chair of Session 2. The session began with an invited address by Manfred Borovcnik, followed by presentations from Judith Stanja (Germany) and Theodosia Prodromou (Australia).

In his talk, "Conditional probability- a review of mathematical, philosophical, and educational perspectives", Borovcnik argued that conditional probability is a key concept in learning and accepting probability and that objective probability alone may not really help to change people's private criteria for dealing with conditional probability problems. He suggested the subjective approach is much closer to how people think and can thus much better explain conditional probabilities. He analyzed the need for teaching strategies to make plausible that conditional probabilities have nothing to do with time and causes, and showed various strategies for solving the Monty Hall problem. Borovcnik also reflected on translating probabilistic questions into absolute (natural) frequencies. His conclusion was that a wider conception of probability might be useful.

Stanja shared her attempt to characterize children's (age 8-9) elementary stochastic thinking by taking the role of semiotic means into account. Some theoretical ideas from Duval were outlined to serve as a basis for her description and analysis of interview data. She particularly stressed the complementarity of artefact and sign in learning probability and assessing child's understanding.

Prodromou addressed issues regarding the possibilities and challenges of using a computer-based modelling approach in the teaching of probability to 15 year-old students. In her investigations she particularly focuses on how the modelling approach can be used for building links between variation, theoretical models, simulations, and probability. Her results suggest that the way students express the 
relationship between signal and noise is of importance while building models from the observation of a real situation.

Summing up the session, Nilsson stressed the need to develop research methodologies in order to investigate the semiotic nature of teaching and learning probability. Approaching the teaching and learning through mathematical modelling seems timely. In Prodromou's study this was made in a computer-based learning environment. The session challenged research to develop real-world approaches for the teaching of probability through mathematical modelling.

\section{Session 3: Probability Literacy and Instructional Challenges}

Enriqueta Reston was the chair of Session 3. The session began with an invited address by Iddo Gal, followed by presentations from Hongshick Jang (Korea), Taek-Keun Oh and Kyeong-Hwa Lee (Korea).

Gal sketched an outline of probability literacy, its development, needs and connections to frameworks of adult competencies and mathematics curricula. He defined probability literacy by knowledge elements and dispositional elements and explained their relationships to both internal and external goals of probability education. To meet external demand better, he suggested teaching directly for probability literacy by increasing the use of tasks based on real-life problems in teaching and assessment, allowing time for subjective probability, and addressing dispositions and personal sentiments.

Jang suggested that empirical evidence involving the process of mathematical modelling in teaching is helpful to senior high school students' learning of probability. He presented his evidence both in terms of efficiency of teaching and motivation of students, but argued the necessity of mathematical formulation within the various types of uncertainty and the need to go beyond the conventional notion of mathematical modelling.

Oh and Lee addressed the teaching and learning of probability for gifted students. They found that learning through debate in solving probability tasks can be valuable for developing creativity of gifted Grade 11 students as the process stimulates flexibility, elaboration, and originality.

In summarizing the session, Reston reflected on whether there is any consensus on the meaning of probability literacy. Moreover, how does it relate to mathematics literacy? Statistical literacy? What are the overlaps? What are the gaps, if any? She also raised questions regarding what concrete actions and future directions will enable us to address instructional challenges in developing probability literacy among our students. 


\section{Session 4: Teacher Knowledge in Probability Teaching}

Kyeong-Hwa Lee chaired the final session. After the presentations by Enriqueta Reston (Philippines), Per Nilsson (Sweden) and Egan Chernoff (Canada) the session ended with a panel debate on Teacher Knowledge in Probability Teaching.

Reston described a study exploring elementary mathematics teachers' conceptions of probability through inductive teaching and learning methods. As a background, she elaborated on the diversity of possible inductive teaching methods including, for instance, inquiry teaching, problem-based teaching and investigations.

Based on a survey study approach, Nilsson investigated correlations between Swedish teachers' content knowledge of probability and their level of education, teaching years and self-assessments of probability concepts. He found that the teachers have low confidence in understanding probability and have difficulties in applying the concepts in probability tasks.

Chernoff reported on research using the attribute substitution model to account for certain normatively incorrect responses of prospective teachers' understanding of random behaviour generated from a series of coin flips. His study considered individuals who, when presented a particular question, answer a different question instead. He argues that making connections between mathematics education and other domains of research will give mathematics education researchers new insights.

Before the Plenary Panel, Lee reviewed the meaning of knowledge for teaching given by Shulman in 1980s and Ball after 2000. During the panel time, Burrill, Kapadia and Borovenvik shared with all participants their insights on this topic.

Burrill choose teachers' pedagogical content knowledge for teaching probability as her main point. She indicated that having deep understanding of content knowledge is crucial for teaching. Teachers' knowledge of students and their ways of thinking about probability are essential as well. She recommended the Common Core State Standards for mathematical practices as a frame for engaging students in probability tasks and highlighted key points for teaching probability to teachers. Kapadia addressed teachers' content knowledge and pedagogical content knowledge as well. To develop probabilistic understanding, he appealed for investigations of teachers' knowledge across different countries with shared instruments. Borovcnik examined seven sources from which teachers could obtain their knowledge. He called for enhanced teaching of probability at the university level and connecting that closely to pedagogical issues, for example, to provide wellorganized textbooks, which highlight modeling and other important ideas and to discuss the origins of students' misconceptions and how to use these in teaching to build understanding. He also listed and commented on several journals, websites of statistical associations and e-platforms he thought could be used to support teachers' development of probabilistic reasoning.

Several papers were presented in poster form: Haneet Gandhi, India; Zhengwu Long, China; Robyn Ruttenberg-Rozen, Canada; Narita, Masahiro, Japan; Tânia M. 
M. Campos, Rosana Nogueira de Lima and Verônica Yumi Kataoka, Brazil; Natsumi Sekiya, Japan; Franziska Wandtner, Goetz Kersting, Reinhard Oldenburg, Germany; Michimasa Kobayashi, Japan. The posters elicited further discussion on the organizing themes of the sessions.

Time for formal presentations and discussions is always very limited at an international conference. But we are convinced that the work of the group initiated discussions on critical areas in probability education, such as teachers' knowledge for teaching, that will attract further investigations and support collaboration among people who are interested in the teaching and learning of probability.

Open Access This chapter is distributed under the terms of the Creative Commons Attribution Noncommercial License, which permits any noncommercial use, distribution, and reproduction in any medium, provided the original author(s) and source are credited. 